\title{
The Origins of Conflict in Polycentric Governance Systems
}

Mark Lubell, UC Davis (mnlubell@ucdavis.edu)

Jack Mewhirter, University of Cincinnati

Ramiro Berardo, Ohio State University

John Scholz, Florida State University

Prepared for delivery at the Workshop on the Ostrom Workshop (WOW6) conference, Indiana University Bloomington, June 19-21, 2019. (C) Copyright 2019 by author"

\begin{abstract}
Natural resources are governed by polycentric systems, which can be theorized as an "ecology of games” where policy actors participate in multiple policy institutions governing interdependent issues. This article analyzes why actors perceive different payoffs across the games in which they participate, ranging from mutually beneficial games of cooperation to conflictual, zero-sum games where one actors' gain means another actor's loss. Hypotheses are developed at the level of the individual, the forum, and the overall polycentric system. The hypotheses are tested through surveys of water governance actors in three different research sites: Tampa Bay, Florida; the Parana River delta, Argentina; the San Joaquin-Sacramento Delta, California. The empirical findings suggest that policy forums will have more conflict when the actors within them are concerned with hot-button issues, when the forums have large and diverse memberships, and in systems with a long history of conflict.
\end{abstract}




\section{The Origins of Conflict in Polycentric Governance Systems}

California water governance, one of the empirical cases for this article, is famous for its pithy adages. During the CALFED era (1984-2009), the mantra was “getting better together”, in reference to the collaborative approach to environmental governance epitomized by CALFED (Doremus 2009; Lubell, Gerlak, and Heikkila 2013). But as is often the case with policy forums, CALFED was dismantled in 2009 and replaced by the Delta Stewardship Council, tasked with developing management plans to achieve the "co-equal goals” of sustainable natural ecosystems and reliable water supply infrastructure (Frank 2010). On the flip side of the coin to these collaborative ideals, another common mantra of California water policy is "whiskey is for drinking, water is for fighting.” Misattributed to Mark Twain, this saying is invoked so frequently that it is in danger of becoming a self-fulfilling prophecy (Fleck 2016). From a governance perspective, these sayings represent the extremes of a continuum of perceived interactions ranging from strong cooperation to all-out conflict.

The preceding anecdotes illustrate the main question of this article: why do stakeholders perceive different levels of conflict and cooperation in polycentric governance systems? Many public administration, policy, and political science researchers now agree that polycentricity“many centers of decision making which are formally independent of each other (Ostrom et al. 1961, p. 831)”- is an inherent feature of most governance systems (Aligica and Tarko 2012; Carlisle and Gruby 2017; McGinnis and Ostrom 2012). However, there is a lack of research in to the specific drivers of different levels of conflict and cooperation in polycentric systems.

Answering this question provides insights into core themes in public administration and management. Polycentric systems epitomize the "disarticulation of the state” (Fredrickson 1999: 
702), where the incongruence between public management problems and jurisdictional boundaries entails interdependence and requires cooperation among a myriad of governmental and non-governmental stakeholders. For theories of collaborative governance (Ansell and Gash 2008; Emerson, Nabatchi, and Balogh 2012), rather than analyzing a single collaborative forum in isolation, polycentricity considers the multiple collaborative forums that exist in a system. Theories of network governance (Klijn, Steijn, and Edelenbos 2010; Provan and Kenis 2008) analyze how networks of actors participate in many different forums, where "the network manager seeks to achieve cooperation between actors while preventing, minimizing, or removing blockages to cooperation (Agranoff and MacGuire 2001).” "Actor-centered institutionalism” (Scharpf 1997) recognizes the reality that actors play many varieties of games with different players, diverse payoffs, and varied levels of conflict. Decisions made in one policy game may change the payoffs in other games, and the strategies that actors choose to play in one game may be transported, sometimes inefficiently, into the context of other games (Bednar and Page 2007). Polycentric governance also embraces the wider concept of complexity theory, which requires analyzing factors that support self-organization (Cairney 2012; Comfort 1994; Iborra et al. 2017) and the interactions between multiple subsystems (McGee and Jones 2019). These diverse streams of public administration scholarship reinforce the importance of developing theory and empirical analysis of conflict and cooperation in complex, polycentric systems.

The recently updated ecology of games theory (EGT; Lubell 2013; Berardo and Lubell 2019) provides a theoretical basis for analyzing conflict and cooperation in polycentric systems. The EGT describes how individual actors participate in one or more policy forums with jurisdiction over different policy issues. Policy forums are defined by the set of informal and formal rules that govern participation and collective decision-making within the forum. In each 
forum, actors have different perceived payoffs ranging from mutually beneficial outcomes (i.e.; getting better together) to zero-sum games where one actor's gain means another actor's loss (i.e.; water is for fighting). This article develops hypotheses about perceived payoffs at the level of individual actors, policy forums, and the overall system.

The hypotheses are comparatively tested using survey data collected from policy actors involved in water governance at three different research sites: Tampa Bay, Florida; the Parana River delta, Argentina; and the San Joaquin-San Francisco Delta, California. The surveys ask water governance actors to describe the payoffs they experience for each forum in which they participate. At the level of individual actors, payoffs could reflect the types of issues an actor cares about, the type of organization that they represent, or their level of experience. At the policy forum level, payoffs could be affected by the number of players, the heterogeneity of organizations, or the heterogeneity of issues under consideration. At the system level, payoffs could be affected by the level of connectivity between a particular forum to other forums in the system, and the overall history of conflict and cooperation in the system.

Before continuing, it is important to clarify our usage of some key theoretical terms from the EGT. Actors are the organizations and individuals who participate in environmental governance processes, and may include both governmental and non-governmental organizations. Issues are the underlying collective-action problems that create environmental problems like water supply, water quality, and others. Policy forums are the social spaces where stakeholders make collective decisions about the policies governing the issues. The EGT treats the terms policy institutions and policy forums as synonyms; the "institutions" term reflects the fact the collective-choice processes are governed by formal and informal rules (Ostrom 1990; Ostrom 2009a). A policy game occurs when actors participate in a policy forum and make actual 
decisions about the issues. The key dependent variable in this paper is the payoffs that actors perceive are available in each policy forum in which they participate.

\section{The Multiple Levels of Polycentric Systems}

To analyze the factors that influence perceived payoffs, this section develops hypotheses at three levels of polycentric governance systems: individual actors, policy forums, and systems. At the individual level are the policy preferences, organizational incentives, and issue concerns of specific actors. At the forum level are the number of actors, the heterogeneity of issues under consideration, and heterogeneity of organizational types. At the system level is the extent to which a policy forum is linked to other parts of the system, along with the history of conflict in a system. The discussion below frames the hypotheses in terms of what factors lead actors to perceive more conflict; the empirical analysis employs an ordered dependent variable ranging from cooperation to conflict.

\section{Actor Level Hypotheses: Issue Concerns and Organizational Types}

Actors in water governance systems usually care about one or more issues such as water supply, water quality, biodiversity, land-use, climate change, flooding or other issues. In any particular context, one or more these issues may become a "hot button" issue that generates more conflict than average. Hot button issues are usually placed higher on the political agenda and deliberated in more central and authoritative forums (Baumgartner and Jones 1991). Exactly which issues generate conflict will vary across different social-ecological systems. For example, the Mediterranean climate of the CA Delta has created enduring conflict between water supply, water quality, and biodiversity (Hanneman and Dyckman 2009). Tampa Bay has historically had an adequate water supply, but the development impacts of the second largest urban area in 
Florida has caused conflict between water quality and land-use decisions (Berardo and Lubell 2016). In the Parana River delta (Argentina), there has been ongoing conflict over land-use in the delta as agricultural producers and cattle ranchers clear native vegetation in the delta's islands to expand production (Baigun et al. 2008; Berardo, Olivier and Lavers 2015). Actors who are concerned about "hot button" issues are more likely to perceive conflict.

Hot Button Issues Hypothesis (H1): Actors who are concerned about "hot button" issues are more likely to perceive conflict.

This article is primarily concerned with policy actors representing different types of organizations involved in important planning processes and policy forums. Researchers in the advocacy coalition framework tradition would call these actors "policy elites” (Jenkins-Smith, Silva and Gupta 2014) interacting at what the institutional analysis and development framework would call the "collective choice" level of governance (Ostrom and Walker 2000). Depending on the type of organization they represent, these actors have different policy preferences and face different political incentives.

Some policy actors emphasize a more neutral or brokering strategy that attempts to find compromise among competing interests. Government bureaucracies often pursue this strategy, as evidenced by their frequent sponsorship of collaborative forums like CALFED, or the oft-heard anecdote that government agencies know they are being effective when all stakeholders are “equally unhappy”. Scientific researchers also generally attempt to adhere to a more neutral role, where they provide information that allows decision-makers to clarify the consequences of their choices (Fischer and Schalpfer 2017). 
Other actors take on a more advocacy role where they prefer a specific distribution of water resources, for example emphasizing ecological sustainability versus water supply reliability. Chief among advocacy actors are environmental and economic interest groups, who typically have conflicting policy preferences (Mewhirter, McLaughlin and Fischer 2019; Newig and Fritsch 2009). Specifically in water, local special water districts and environmental districts also frequently advocate for their more narrow policy interests rather than play the neutral brokering role of other government actors.

Neutral Actors Hypothesis (H2): Governmental and scientific actors will perceive less conflict than actors with advocacy interests such as interest groups and local special districts.

\section{Policy Forum Hypotheses: Group Composition and Issue Diversity}

To analyze how the attributes of policy forums affect perceived payoffs, we adapt the transaction cost perspective utilized in many studies of institutions (Blore, Cundill and Mkhulisi 2013; Coggan et al. 2013; Mewhirter, Coleman and Berardo 2017; North 1990). The transaction cost approach argues that cooperation is more likely when the transaction costs are lower for searching for mutually beneficial policy agreements, bargaining over the costs and benefits of those agreements, and monitoring and enforcing the resulting policies. We adapt this idea by arguing that complex governance systems have multiple policy forums, each of which offer an opportunity for finding potentially mutually beneficial agreements. For example, in a previous analysis we found that the perceived adequacy of scientific knowledge was correlated with 
perceived policy effectiveness, which is consistent with the idea that better scientific information reduces transaction costs (Lubell et al. 2017).

Here we focus on the mix of issues and actors that are at hand in a policy forum. Policy forums involve many actors with different organizational cultures and backgrounds (Hardy and Koontz 2009). One of the most venerable hypotheses in the collective action literature is that cooperation is more difficult with more actors (Bonacich et al. 1976; Olson 1965). In addition, transaction costs are higher when the diversity of organizational types is greater (Fischer and Leifeld 2015; Fishcer and Schlapfer 2017; Heckathorn 1993; Poteete and Ostrom, 2004). Most public policy domains include government agencies from all levels of government, interest groups, universities, elected officials, and many other types of actors. Each actor may have different organizational capacities and policy preferences, which increases the bargaining costs of finding a policy decision that is considered fair by all stakeholders (Provan and Kenis 2008).

Group Composition Hypothesis (H3): Policy forums with larger and more diverse sets of actors will generate higher levels of perceived conflict.

Another basic assumption of the EGT is that policy forums will often involve more than one underlying policy issue caused by some type of substantive collective-action problem such as the overexploitation of a common-pool resource or provision of a public good. In the water management context of this paper, policy issues include water supply, water quality, flood management, biodiversity, and climate change (Berardo and Lubell 2016). Policy issues are often linked via physical, social or economic processes, and thus behaviors affecting one issue can indirectly affect another (Bodin 2017). There is often competition among issues and negative cross-issue externalities, along with high levels of complexity in understanding linkages 
(Mewhirter and Berardo 2019). Due to this complexity, policy forums that address a diverse set of policy issues will feature higher transaction costs.

Issue Diversity Hypothesis (H4): Policy forums that involve a more diverse set of issues will generate higher levels of perceived conflict.

One counter-hypothesis to this argument is that issue diversity may provide opportunities for integrated strategies that increase the potential benefits of cooperation. For example, water management stakeholders often seek institutional arrangements for "conjunctive use” of surface water and groundwater so that groundwater storage can be used as a back-up when surface water is scarce. These types of synergistic strategies are the hallmark of collaborative environmental governance (Beierle and Konisky 2001; Kim and Siddiki 2018), and the associated concepts of ecosystem, watershed, adaptive, and integrated water resources management (Mewhirter, McLaughlin and Fischer 2019). To the extent issue diversity provides opportunities for integration and synergistic benefits, cooperation may be enhanced but only if the development of integrative strategies is able to overcome the inherent complexity of linked issues.

\section{System Level Hypotheses: Institutional Linkages and History of Conflict}

A core concern of the EGT is how different policy forums are linked together throughout the system. Young (2002) refers to this as the idea of institutional interplay—decisions made in one policy forum can impose positive of negative institutional externalities on other policy forums. One way policy forums are linked is when the same actor participates in two different forums (McGinnis 2011). The experiences that an actor has in one forum can affect their strategies and payoffs in the other forum (Bednar and Page 2007). This can be viewed from a network perspective — policy forums with many different joint actors are more embedded in the 
network of institutions that exists in the system. Hence, the extent to which a particular policy forum is linked to others provides information on how the overall system impinges on the perceived payoffs in a focal forum.

There are two competing hypotheses about how institutional linkages could affect payoffs. One the one hand, institutional linkages could create more conflict because policy forums that are linked to many other forums will experience a high level of institutional externalities and uncertainty about how decisions made in the system will affect the decisions made in a focal institution. These forums are essentially a victim of institutional fragmentation and high transaction costs in the system, and thus more likely to experience conflict.

Alternatively, many of the policy forums that have high levels of institutional linkages are in fact collaborative institutions that explicitly seek to enhance cooperation. These collaborative institutions often emerge when stakeholders become frustrated with the status quo conflict inherent in a fragmented system. They will participate in the new institution to remedy the conflict, and capture gains from cooperation that were otherwise unavailable. From this perspective, collaborative institutions help ease transaction costs throughout the system (Lubell 2015). This leads to the following competing hypotheses:

Institutional Linkages Hypothesis (H5): Policy forums with higher levels of institutional linkages will have either more conflict, or more cooperation.

The evolution of polycentric systems is constrained by social-ecological context (Ostrom 2009b; Bodin 2017), and characterized by path dependence where earlier experiences have strong legacy effects on current processes (Pierson 2000). Some of these contextual and legacy effects are difficult to measure and estimating their association with perceived 
conflict would require far more cases than we have in this study. For example, testing the hypothesis that some measurement of ecological complexity was linked to higher levels of conflict would be more conclusive if the variance in ecological complexity was observed over many contexts.

However, it is feasible to rely on substantive knowledge to anchor a comparative analysis across a smaller number of systems. In this study, we know that California has a long history of recurring water conflict that is emblematic of water management in the Western United States (Lubell, Gerlak, and Heikkala 2013). These conflicts have involved multiple issues, especially water quality, water supply, biodiversity, and invasive species, driven by social-ecological variables associated with California’s high levels of urban and agricultural development and highly variable Mediterranean climate. Although Tampa Bay (water quality and loss of sea-grass) and the Parana Delta (extreme events including floods and man-made fires, and rapid urbanization particularly in the lower section of the delta) are not without conflict, they do not have the same level of conflict as California, or as many policy forums that have emerged to collectively address those conflicts. The history of conflict in California leads to our final hypothesis:

High-conflict Systems Hypothesis (H6): California actors will perceive a significantly higher level of conflict than Parana or Tampa Bay.

\section{Empirical Case Studies: A Comparative Analysis Complex Water Governance Systems}

We investigate these hypotheses via a comparative quantitative analysis of three water management contexts: San Joaquin-Sacramento Delta in California (CA Delta), Tampa Bay in Florida, and Parana Delta in Argentina. Each of these cases focuses on water management of an 
estuary ecosystem, where freshwater from a river system enters the coastal salt water. Each of these estuaries are governed by a multitude of institutions involving hundreds of policy actors. In short, each study area is a good example of polycentric governance in action.

However, while we do not claim to have a clean quasi-experimental design, these estuaries vary in important ways. While many of the CA governing institutions are welldeveloped, they have also been changing quite quickly during the period of our study. For instance, one of the central policy institutions called CALFED was dismantled in 2009 and replaced by the Delta Stewardship Council; this represents a "recentralization" of the institutional arrangements with the new institution given more authority to compel the behavior of state agencies.

Tampa Bay, FL is a well-developed but more centralized and less complex ecology of games. There are fewer overall institutions in Tampa Bay, and those institutions are heavily dominated the Southwest Florida Water Management District (Mewhirter, Coleman and Berardo 2017). The Florida water management districts are unique agencies in the United States because they have the authority to implement many of the state and Federal water management laws. Thus they become the organizational "host" to a number of different policy forums, including both collaborative and regulatory institutions. Tampa Bay has not experienced as severe of conflict as California and is not going through as much institutional change.

The Parana River delta presents an interesting contrast to the United States estuaries because it is in an earlier stage of institutional development. During the period of our study, many of the institutions that did exist in the area to regulate the use of natural resources in this large system were only temporary (and in many cases just ephemeral), focusing mostly on 
information sharing rather than establishing strong operational rules governing access to, and use of, resources. There is one large management program in the Delta which was created by the federal and the provincial governments of Santa Fe, Buenos Aires, and Entre Ríos in 2008 (the three provinces share the delta). Named the Comprehensive Strategic Plan for the Conservation and Sustainability of the Paraná River Delta (PIECAS in Spanish), the plan was supposed to be a major effort to improve the management of natural resources in the delta by harmonizing provincial legislation, securing public participation in decision-making processes, and achieving sustainability goals while furthering social justice (see Berardo, Olivier and Lavers 2015 for more details on the plan).

Taken together, the empirical case studies represent ecologies of games at different stages and trajectories of institutional evolution. Parana has a nascent set of institutions, while California and Tampa Bay have a much higher level of development. But California has developed many decentralized institutions, characterized by cycles of intense conflict. Tampa Bay has developed a fewer number of more centralized institutions, potentially with less conflict. The differences between California and Tampa Bay highlight the availability of multiple pathways of institutional development; the exact pathways take depend on many contextual factors such as the types of resources and macro-level political institutions.

\section{Methods: Water Management Stakeholder Survey and Variable Construction}

Mixed survey methods applied to all three regions generated the data on policy forum participation and perceptions. Web and media-based searches were used to identify all major water-related policy forums. Most of the major forums contain some types of participant lists in various locations; these were scraped to develop the sample database. The same survey 
questionnaire (with Spanish translation for Parana) was applied to the three research sites. The survey was fielded in California from 2/18/2011 through 6/14/2011; Tampa Bay from 11/17/2010 through 2/7/2011, and in Argentina from 10/12/2010 through 12/21/2010.

In Tampa Bay, the original list of 966 names with available email addresses was extended by a snowball question in the survey that yielded an additional 71 names for a total of 1037 possible respondents. Using the 97 respondents who reported ineligibility in the screening questions to estimate the number of eligible names among the 504 who did not respond at all to the email, the AAPOR RR4 estimated response rates vary from 32\% to 37\% depending on the estimation method. In the Sacramento-San Joaquin delta the original list of 1368 names was extended by snowball questions to 1494, of whom 319 submitted surveys, 42 refused, and 152 self- reported ineligibility. Using the same calculations as for Tampa, comparable response rates varied from $31 \%$ to $36 \%$.

In Parana, a total of 261 individuals were identified and contacted over the phone to answer the survey by Gestion Consultora, a survey company based in the city of Cordoba. We decided to administer the survey over the phone in Argentina given the likely lower percentage of individuals with access to the internet. Of these, 177 answered our questions, for a response rate approximating $68 \%$.

\section{Identifying Policy Forums}

Each respondent could identify up to fifteen policy "forums" they were actively involved in during the past year. This question is similar to a name-generator network elicitation question (Marsden 1990). The phrase "forums and planning processes" operationalizes the idea of a policy forum in a vernacular familiar to respondents, with the following definition: "Planning 
processes are defined as forums where stakeholders make decisions about water management policies, projects, and funding.” Lubell et al (2012) used a similar question to represent the linkages between actors and forums as a bi-partite social network. The number of times a policy forum is mentioned is equivalent to the degree of that forum in a policy network; high degree is one measure of centrality in a network.

This paper aggregates these responses to the level of individual policy forums. The respondents provided the names of each forum, which were hand-coded to group together forums that were named in different ways. For example, one respondent might write-out the full name of the Southwest Florida Water Management District, while another would write SWFMD. Below we describe the variables used to test our hypotheses. Summary statistics for all variables are provided in Table A1 in the Appendix.

\section{Dependent Variable: Perceived Payoffs}

To measure perceived payoffs, the survey asked each respondent the following question for each policy forum in which they indicate participation:

Which of the following statements best characterize the typical decision processes about water-related issues in each forum in the past year?

1. (Mutually Beneficial) For most decisions in this forum, most groups can gain as long as they can develop a common policy.

2. (Kaldor-Hicks Trade-offs) Although most groups can gain from most decisions, there is conflict over who will gain the most.

3. (Zero-Sum) For most decisions, one group's gain involves another group's loss.

The first option means the payoff is perceived to be mutually beneficial, or Pareto-improving in the language of game theory. The second option captures a potential Pareto-improvement, where the involved players have an overall gain but some losers would potentially need to be 
compensated. This is loosely related to the Kaldor-Hicks efficiency principle the decisions lead to gains for most groups (Pareto-improvements), but there is conflict over the distribution of gains and the extent to which any losers could be compensated (Buchanan 1965). The third option is a zero-sum game where any one group's gain is at the expense of another groups; this is the highest level of conflict.

\section{Independent Variables: Individual Level}

We test $\mathrm{H} 1$ by asking each respondent to indicate the extent to which they deal with each of the following issues: water supply, water quality, flood management, land-use, biodiversity, and climate change. We identified "hot button" issues from substantive understanding of each estuary as well as Chi-square tests of whether stakeholders indicating a particular issue expressed significantly more zero-sum conflict payoffs. The "hot-button" variable indicates the number of the following issues that an actor works on in each estuary: land-use (Parana, Tampa), water quality (Tampa, California, Parana), water supply (California), and biodiversity (California). Values range from $0-3$, where 0 indicates an actor works on no hot button issues, and a score of 3 indicates that they work on three hot button issues.

Each respondent was asked to identify the type of organization they represent from the following list: federal government, state government, regional government, local government, water infrastructure special district, environmental special district, environmental group, trade/business/industry group, homeowner association, education/consulting/research, multistakeholder coalition, political party, recreational group, agriculture, and media. To test $\mathrm{H} 2$, we create a dummy variable for "neutral organizations" that includes federal, state, regional, and local governments as well as researchers. The other types of organizations are considered playing 
a potential advocacy role of some type. Respondents who indicated participating as unaffiliated individuals were classified in the advocacy category.

\section{Independent Variable: Policy Forum Level}

Testing the group composition hypothesis (H4) requires measuring the number and diversity of actors in each policy forum. To measure the number of actors in a particular policy forum, we take the sum of the respondents who mention participating in a particular policy forum. The minimum count is one in all study sites, with a maximum of 102 in the CA Delta, 38 in Tampa Bay and 42 in Parana. Note that this is an undercount of the true number of actors who participate in a particular forum; survey non-response prevents observing all of the actors. However, the measure is proportional to the number of participating actors if they could be fully observed.

To measure organizational diversity, we use the inverse Hirschman-Herfindahl index (IHI) that considers the proportion of policy actors who represent organizations of different types, using the following formula: $1-\sum_{i=1}^{N} s_{i}^{2}$, where $s_{i}$ is the proportion of actors representing a particular type of organization. The HHI ranges from $0-(1-1 / N)$, with higher numbers indicating greater diversity of actors. One interpretation of the HHI is the probability that two randomly selected actors belong to the same category, in this case belong to the same organizational types. The HHI was originally developed to measure market concentration for firms (Boydstun, Bevan, and Thomas 2014), and has also been used to measure ethnic diversity in cities or other geographic units.

We measure issue diversity in parallel fashion by constructing the IHI on the basis of the issue involvement of the actors in a particular forum. If an actor participating in a policy forum is 
concerned about a particular issue (e.g.; water supply), then we assume the policy forum addressing that issue. The issue diversity measure is used to test $\mathrm{H} 4$.

\section{Independent Variables: Institutional Linkages at the System Level}

We measure how a particular focal policy forum is linked to other policy forums in the system via joint forum participation of actors in proportion to the number of participants in the focal forum. For example, if a forum consists of two actors, each of which participate in three forums (the focal forum and two others), the institutional linkage variable would take a value of 2: the total number of linkages to other forums (4), divided by the number of participants in the focal forum (2). From a technical perspective, this score is calculated by constructing the onemode projection of a two-mode network where respondents are linked to forums, and then dividing that number by the number of actors in question. In doing so, the measure captures the extent to which a system is embedded within a governance system. Adjusting for the number of number of actors allows us to separate out the effects of institutional linkages from forum-size (measure discussed above). Whereas the total number of share connections is highly correlated with forum size ( $\mathrm{r}=.99)$, the proportional measure is not $(\mathrm{r}=.12)$.

\section{Descriptive Analysis: Perceived Payoffs across Study Sites}

Table 1 reports the average frequency of different payoffs across all games by site. Tampa has the highest percentage of mutually beneficial payoffs, California has the highest frequency of zero-sum payoffs, while Parana has the highest frequency of Kaldor-Hicks payoffs. This suggests that California is experiencing the most conflict, while Florida has the most cooperation and Parana is somewhere in between.

[Table 1 about here: Percentage of respondents mentioning different payoffs] 
Figure 1 demonstrates the extent to perceived payoffs vary across actors that work for advocacy organizations v. neutral organizations as well as actors that work on at least one hot button issue versus those that work solely on uncontroversial issues. A series of $X^{2}$ tests show that actors representing "neutral" organizations are more likely to report zero-sum payoffs ( $\mathrm{p}=.001)$, less likely to report mutually-beneficial payoffs ( $\mathrm{p}=.002$ ) and equally likely to report trade-off payoffs $(\mathrm{p}=.910)$. Similarly, actors that deal with at least one hot button issue are more likely to report zero-sum payoffs ( $\mathrm{p}=.023)$ less likely to report mutually-beneficial payoffs $(\mathrm{p}=.029)$ and equally likely to report trade-off payoffs ( $\mathrm{p}=.732)$.

\section{[Figure 1 about here: Distribution of Payoffs for Individual Organizations and Issues]}

\section{Multivariate Analysis}

To provide a more comprehensive joint test of all hypotheses, we estimate an ordered logistic regression (see Appendix for various robustness tests and alternative model specifications) where the dependent variable is the payoff perceived by the respondent for each policy game in which they participate. The variable is coded in ordered discrete values where 1=mutually beneficial; 2=trade-offs; and 3=zero-sum. The ordered variable assumes an underlying dimension of cooperation to conflict. The analysis is limited to games that have more than 2 players, because the measurement of issue and organizational diversity requires that each forum have two or more actors present.

The independent variables are defined above, with some variables at the individual level, and others at the forum level. The institutional linkage variable is unique to each forum, but is derived from how the forum is connected to other forums in the system. The model includes dummy variables for each estuary site to test how the sites vary in terms of overall levels of 
conflict, reflecting the history of the system related to variables not explicitly measured in our analysis of the governance system. We include two control variables measured at the actor-level to adjust for the extent to which an actor concentrates their effort in each forum. We do so by including variables indicating frequency by which an actor attends each forum (1=Daily; 2=Weekly; 3=Monthly; 4=Quarterly; 5=Yearly), as well as the total number of forums in which they participate.

Table 1 shows the coefficient estimates. The results at the actor level are consistent with Hot Button Issues Hypothesis. For every additional hot-button issue an actor works on, the model predicts a 0.230 increase in the log-odds of perceiving a higher level of conflict within a given forum. To put this in context, when holding all other variables at their means, an actor that has a hot-button issue score of 0 has a $60.24 \%$ chance of perceiving mutually beneficial payoffs, whereas an actor that has a hot button issue score of 3 only has a $44.53 \%$ chance. Similarly, an actor that has a hot-button issue score of 3 has a $23.27 \%$ chance of perceiving zero-sum payoffs, whereas an actor that has a hot button issue score of 0 only has a $13.70 \%$ chance. We find no support for the Neutral Organization Hypothesis. In line with previous finding, actors who are frequent participants in forums are also more likely to perceive cooperative payoffs.

\section{[Table 2 about here: Ordered Logistic Regression Results]}

At the forum level, the model supports the Group Composition Hypothesis, as both group size and diversity of group membership significantly impact the probability that respondents perceive greater levels of conflict. To elucidate, participants in a forum with 5 members (first quartile) have a $56.68 \%$ chance of perceiving payoffs to be mutually beneficial and a $14.93 \%$

chance of perceiving zero-sum payoffs: participants in a forum with 34 members (third quartile) 
have a $48.60 \%$ chance of perceiving payoffs to be mutually beneficial and a $19.67 \%$ chance of perceiving zero-sum payoffs.

Similarly, participants in a forum with an inverse Hirschman-Herfindahl Index (IHI) score of .625 (first quartile) have a 53.27\% chance of perceiving payoffs to be mutually beneficial whereas those in forums with an IHI value of .82 (third quartile) have a $47.99 \%$ chance. Conversely, participants in a forum with an inverse IHI score of .625 have a $17.76 \%$ chance of perceiving payoffs to be zero-sum whereas those in forums with an IHI value of .82 have a $20.95 \%$ chance.

At the system level, while there is no support for the Institutional Linkages Hypothesis, the dummy variables for each research site confirm the basic pattern of payoffs observed in Table 1. Respondents in Tampa and Parana are indistinct with regard to perceptions of payoffs, whereas individuals in California have an increased likelihood of perceiving higher levels of conflict. These results suggest that the specific context and history of conflict (H6) in different social-ecological systems has a large influence on the dynamics of polycentric institutions.

\section{Discussion}

How stakeholders perceive the payoffs available in the multiple policy forums that constitute polycentric governance systems is a key indicator of levels of cooperation and conflict. The results suggest that conflict is a function of individual, forum, and system-level variables. Forums that address salient, hot-button issues experience higher levels of conflict, although experienced policy actors who frequently participate in the forum perceive more gains from cooperation. Group composition is a strong driver of conflict—conflict is higher in policy 
forums with many players representing diverse organizations. Issue diversity has a negligible effect, and if anything is associated with more trade-offs and less conflict.

The extent to which policy forums are linked to the broader system via co-participation does not appear to affect conflict. This finding contrasts with previous work that suggests actors mostly perceive their linkages to other forums as generating negative externalities (Mewhirter, Lubell, and Berardo 2017). It may be the case that the transaction costs of additional forums are balanced by new opportunities to cooperate, or that some linkages to other forums stimulate cooperation while others engender conflict. To the extent system linkages vary in their effects, more refined theory and empirical analysis is needed to shed light on the mechanisms via which conflict and cooperation spreads across the system.

However, the analysis does provide considerable evidence of differences across socialecological systems. While cooperation is the dominant payoff in all sites, California is clearly experiencing the highest level of conflict. This is expected given California's ongoing "water wars” and nearly continuous flux of policy institutions at all levels of government. Climate change and the predicted increase in climate variability (i.e.; more extreme wet/flood and dry/drought periods) will only accelerate this process. Tampa Bay has witnessed a much lower level of conflict and has more stable institutions. The higher level of trade-offs apparent in Parana may be indicative of a system with a lower level of political and institutional development, or cultural differences in strategies of cooperation. The system-level results also lend credibility to our measurements of perceived payoffs as an empirical approach to gauging the level of conflict in different systems and potentially over time.

\section{Conclusion}


What does this article contribute to public administration theory and practice? Most proximally, the analysis reinforces the usefulness of EGT as a theoretical approach to disentangling the drivers of conflict and cooperation in polycentric systems. The EGT points out the necessity of analyzing the full constellation of actors, policy forums, and issues that exist in polycentric systems. The EGT also usefully decomposes drivers of conflict into three levels of the system—individual, forums, and overall system. The decomposition provides a pathway for integrating concepts like transaction costs into an empirical analysis of cooperation and conflict.

More broadly, among the many public administration theories alluded to in the introduction, the analysis provides the most insights for collaborative and network governance. The largest and most central forums in the systems rely on some type of collaborative approach (Lubell, Robins, Wang 2014) that espouses the ideals of principled engagement, joint capacity, and shared motivations (Emerson et al. 2012). Yet this article demonstrates that increasing the number and heterogeneity of actors participating in a forum breeds conflict. This means that large-scale collaborative forums, which are the "biggest games in town" for polycentric systems, must function primarily as venues for conflict resolution. However, this does not mean collaborative governance fails because it is extremely difficult to observe the counterfactual in these systems. What would have happened in the absence of the set of collaborative governance institutions, where many participating organizations see conflict? It is possible that the overall level of conflict in the system could be even higher without some of these collaborative institutions.

Network managers seeking to steer polycentric systems towards more collaboration must consider the challenges of polycentric systems, including the creation and structure of policy forums, and patterns of participation. As evidenced by the presence of professional mediators in 
many collaborative forums, conflict resolution strategies can be beneficial. When inviting heterogeneous organizations, it is critical to think about values and strategies of the individuals who represent those organizations_-are they individuals who are willing to collaborate, trustworthy, and share the values of inclusiveness that are espoused by collaborative approaches? Individuals with a positive reputation and experience in the system, along with seniority in their organizations, may also be more effective at navigating conflict. The good news is that another hallmark of collaborative governance, the attempt to integrate across issues and find mutually beneficial trade-offs, is less problematic. When it comes to institutional design, policy makers should pay the closest attention to group composition and not shy away from trying to manage multiple linked issues.

While this analysis offers some initial insights into the origins of conflict in polycentric systems, much more research is needed to confirm these findings and identify other drivers of conflict and cooperation. We believe that the existence of polycentric systems is a fundamental reality of the "disarticulated state"-it is not a case of monocentric versus polycentric, but rather what are the dimensions along which polycentric systems vary. It is obvious that many historical institutional and ecological factors influence levels of conflict in these systems. Fully understanding these dynamics requires a major research investment in multiple study sites across the globe, with repeated measurements of policy forums, actors, and ecological processes. Such a large-scale, global network of governance observatories would allow researchers to study the temporal dynamics of how conflict and cooperation co-evolve over time with institutional structures, actors' strategies, and social, environmental, and economic outcomes. 


\section{References}

Aligica, Paul D., and Vlad Tarko. 2012. "Polycentricity: From Polanyi to Ostrom, and Beyond.” Governance 25 (2): 237-62. https://doi.org/10.1111/j.1468-0491.2011.01550.x.

Agranoff, Robert, and Michael McGuire. 2001. "Big Questions in Public Network Management Research.” Journal of Public Administration Research and Theory 11 (3): 295-326.

Ansell, Chris, and Alison Gash. 2008. "Collaborative governance in theory and practice." Journal of public administration research and theory 18(4): 543-571

Baigún, Claudio RM, Alba Puig, Priscilla G. Minotti, Patricia Kandus, Ruben Quintana, Ricardo Vicari, Roberto Bo, Norberto O. Oldani, and John A. Nestler. 2008. "Resource use in the Parana River Delta (Argentina): moving away from an ecohydrological approach?” Ecohydrology \& Hydrobiology, 8(2-4), 245-262.

Baumgartner, Frank R., and Bryan D. Jones. "Agenda dynamics and policy subsystems." The journal of Politics 53, no. 4 (1991): 1044-1074.

Bednar, Jenna, and Scott Page. "Can game (s) theory explain culture? The emergence of cultural behavior within multiple games." Rationality and Society 19.1 (2007): 65-97

Beierle, Thomas C., and David M. Konisky. 2001."What are we gaining from stakeholder involvement? Observations from environmental planning in the Great Lakes." Environment and planning C: Government and Policy 19(4): 515-527

Berardo, Ramiro, and Mark Lubell. 2019. "The Ecology of Games as a Theory of Polycentricity: Recent Advances and Future Challenges." Policy Studies Journal 47(1):6-26.

Berardo, Ramiro, and Mark Lubell. 2016. "Understanding what shapes a polycentric governance system." Public Administration Review 76(5): 738-751 
Berardo, Ramiro, Tomás Olivier, and Anthony Lavers. 2015."Focusing events and changes in ecologies of policy games: evidence from the Paraná River Delta." Review of Policy Research 32(4): 443-464-464

Blore, M. L., Georgina Cundill, and Mazwi Mkhulisi. 2013. "Towards measuring the transaction costs of co-management in Mkambati Nature Reserve, Eastern Cape, South Africa." Journal of environmental management 129: 444-455

Bodin, Örjan. 2017. “Collaborative Environmental Governance: Achieving Collective Action in Social-Ecological Systems.” Science 357 (6352): eaan1114.

Bonacich, Phillip, et al. 1976. "Cooperation and group size in the n-person prisoners' dilemma." Journal of Conflict Resolution 20(4): 687-706

Boydstun, Amber E., Shaun Bevan, and Herschel F. Thomas III. "The importance of attention diversity and how to measure it." Policy Studies Journal 42, no. 2 (2014): 173-196.

Buchanan, James M. 1959. "Positive Economics, Welfare Economics, and Political Economy.” The Journal of Law and Economics 2: 124-38.

Cairney, Paul. 2012. “Complexity Theory in Political Science and Public Policy.” Political Studies Review 10 (3): 346-58.

Carlisle, Keith, and Rebecca L. Gruby. 2017. "Polycentric Systems of Governance: A Theoretical Model for the Commons.” Policy Studies Journal. https://doi.org/10.1111/psj.12212

Coggan, Anthea, Edwin Buitelaar, Stuart Whitten, and Jeff Bennett. 2013. "Factors that influence transaction costs in development offsets: Who bears what and why?" Ecological Economics 88: 222-231 
Comfort, Louise K. 1994. “Self-Organization in Complex Systems.” Journal of Public Administration Research and Theory: J-PART 4 (3): 393-410.

Dekker, David, David Krackhardt and Tom Snijders. 2003. "Multicollinearity robust QAP for multiple regression." 1st Annual Conference of the North American Association for Computational Social and Organizational Science.

Doremus, Holly. 2009. "CALFED and the quest for optimal institutional fragmentation." environmental science \& policy 1(6): 729-732

Emerson, Kirk, Tina Nabatchi, and Stephen Balogh. 2012. “An Integrative Framework for Collaborative Governance.” Journal of Public Administration Research and Theory 22 (1): 1-29. https://doi.org/10.1093/jopart/mur011.

Fischer, Manuel, and Isabelle Schläpfer. 2017. "Metagovernance and policy forum outputs in Swiss environmental politics." Environmental Politics 26(5): 870-892

Fischer, Manuel, and Philip Leifeld. 2015. "Policy forums: Why do they exist and what are they used for?" Policy Sciences 48(3): 363-382

Fleck, John. 2016. Water Is for Fighting over: And Other Myths about Water in the West. Island Press.

Frank, Richard M. 2010. "A New Dawn for the Sacramento-San Joaquin Delta-Assessing the 2009 California Delta/Water Legislation." Ecology L. Currents 37(17).

Frederickson, H. George. 1999. “The Repositioning of American Public Administration.” PS: Political Science \& Politics 32 (04): 701-12. https://doi.org/10.2307/420159.

Jenkins-Smith, Hank, et al. 2014 "Belief system continuity and change in policy advocacy coalitions: Using cultural theory to specify belief systems, coalitions, and sources of change." Policy Studies Journal 42(4): 484-508. 
Erik-Hans Klijn, Bram Steijn, and Jurian Edelenbos. 2010. “The Impact of Network Management on Outcomes in Governance Networks.” Public Administration 88 (4): 1063-82.

Hanemann, Michael, and Caitlin Dyckman. 2009. "The San Francisco Bay-Delta: A failure of decision-making capacity." Environmental Science \& Policy 126: 710-725

Hardy, Scott D., and Tomas M. Koontz. 2009. "Rules for collaboration: institutional analysis of group membership and levels of action in watershed partnerships." Policy Studies Journal 37(3): 393-414

Heckathorn, Douglas D. 1993. Collective action and group heterogeneity: voluntary provision versus selective incentives. American Sociological Review: 329-350.

Iborra, Susanna Salvador, Angel Saz-Carranza, Xavier Fernández-i-Marín, and Adrià Albareda. 2017. “The Governance of Goal-Directed Networks and Network Tasks: An Empirical Analysis of European Regulatory Networks.” Journal of Public Administration Research and Theory 28 (2): 270-92.

Kim, Jangmin, and Saba Siddiki. 2018. "Linking diversity of collaborative policymaking forums with procedural justice perceptions: A study of US marine aquaculture partnerships." The American Review of Public Administration 48(2): 159-174.

Erik-Hans Klijn, Bram Steijn, and Jurian Edelenbos. 2010. “The Impact of Network Management on Outcomes in Governance Networks.” Public Administration 88 (4): 1063-82.

Labianca, Giuseppe, Daniel J. Brass, and Barbara Gray. 1998. "Social Networks and Perceptions of Intergroup Conflict: The Role of Negative Relationships and Third Parties." Academy of Management Journal 41 (1):55-67. 
Lubell, Mark. 2015. “Collaborative Partnerships in Complex Institutional Systems.” Current Opinion in Environmental Sustainability 12: 41-47.

Lubell, Mark. 2013. "Governing Institutional Complexity: The Ecology of Games Framework.” Policy Studies Journal 41 (3): 537-59.

Lubell, Mark, Andrea Gerlak, and Tanya Heikkila. 2013. "CalFed and collaborative watershed management: success despite failure." Making Space for the River: 65-75

Lubell, Mark, Jack M. Mewhirter, Ramiro Berardo, and John T. Scholz. 2017. "Transaction costs and the perceived effectiveness of complex institutional systems." Public Administration Review 77(5): 668-680.

Lubell, Mark, Garry Robins, and Peng Wang. 2014. "Network Structure and Institutional Complexity in an Ecology of Water Management Games.” Ecology and Society 19 (4): 23.

Marsden, Peter V. 1990. "Network data and measurement." Annual review of sociology 16(1): $435-463$

McGee, Zachary A., and Bryan D. Jones. 2019. "Reconceptualizing the Policy Subsystem: Integration with Complexity Theory and Social Network Analysis.” Policy Studies Journal 47 (S1): S138-58. https://doi.org/10.1111/psj.12319.

McGinnis, Michael D. 2011. "Networks of Adjacent Action Situations in Polycentric Governance.” Policy Studies Journal 39 (1): 51-78.

McGinnis, Michael D, and Elinor Ostrom. 2012a. "Reflections on Vincent Ostrom, Public Administration, and Polycentricity.” Public Administration Review 72 (1): 15-25.

Mewhirter, Jack, Eric A. Coleman, and Ramiro Berardo. 2017. "Participation and political influence in complex governance systems." Policy Studies Journal. 
Mewhirter, Jack, Mark Lubell, and Ramiro Berardo. 2018. "Institutional externalities and actor performance in polycentric governance systems." Environmental Policy and Governance 28(4): 295-307

Mewhirter, Jack, and Ramiro Berardo. 2019. "The Impact of Forum Interdependence and Network Structure on Actor Performance in Complex Governance Systems." Policy Studies Journal.

Newig, Jens, and Oliver Fritsch. 2003. "Environmental governance: participatory, multi-leveland effective?" Environmental policy and governance 19(3): 197-214

North, Douglass C. 1990. Institutions, Institutional Change and Economic Performance. Cambridge, UK: Cambridge University Press.

Olson, Mancur. 1965. "The logic of collective action Harvard University Press." Cambridge, MA.

Ostrom, Elinor. 1990. Governing the commons. Cambridge university press

Ostrom, Elinor. 2009a. Understanding institutional diversity. Princeton university press

Ostrom, Elinor. 2009b. “A General Framework for Analyzing Sustainability of Social-Ecological Systems.” Science 325 (5939): 419-22. https://doi.org/10.1126/science.1172133.

Ostrom, Elinor, \& Walker, James. 2000. "Neither markets nor states: Linking transformation processes in collective action arenas.” Polycentric games and institutions, 427-471

Ostrom, Vincent, Charles M. Tiebout, and Robert Warren. 1961. “The Organization of Government in Metropolitan Areas: A Theoretical Inquiry.” The American Political Science Review 55 (4): 831-42. 
Pierson, Paul. 2000. “Increasing Returns, Path Dependence, and the Study of Politics.” American Political Science Review 94 (02): 251-67.

Poteete, Amy R, and Elinor Ostrom. 2004. Heterogeneity, group size and collective action: The role of institutions in forest management. Development and Change 35 (3): 435-461.

Provan, Keith G., and Patrick Kenis. 2008. "Modes of network governance: Structure, management, and effectiveness." Journal of public administration research and theory 18(2): 229-252

Scharpf, F. W. 1997. Games Real Actors Play: Actor-Centered Institutionalism in Policy Research. Westview Press.

Williams, Richard. 2006. “Generalized ordered logit/partial proportional odds models for ordinal dependent variables.” Stata Journal 6: 58-82.

Williams, Richard. 2014. Gologit2/OGLM troubleshooting. Retrieved from http://www3.nd.edu/ rwilliam/gologit2

Williams, Richard. 2016. "Understanding and interpreting generalized ordered logit models.” The Journal of Mathematical Sociology, 40(1): 7-20

Young, Oran R. 2002. The Institutional Dimensions of Environmental Change: Fit, Interplay, and Scale. MIT press. 


\section{Appendix}

\section{[Table A1 about here: Summary Statistics for all Variables Used in Analysis]}

\section{Robustness Tests}

Alternative model specifications serve as a robustness checks on the main findings of the paper presented in Table 1. The first robustness check addresses interdependence within the dataset that, if left unmodelled, could artificially deflate standard errors, increasing the probability of committing a Type I error. Interdependence arises from multiple sources including, but not necessarily limited to: multiple observations per actor; multiple respondents participating in the same forum; forums being sponsored by the same organization; respondents working together outside of forums; forums outputs impacting one another and/or dealing with overlapping policy problems (Mewhirter, Lubell and Berardo 2019). While the first two forms of interdependence can be observed within the dataset, the rest cannot, and thus cannot explicitly be modelled in the regression equation. A random permutation ordered logistic regression can adjust for these issues. A random permutation ordered logistic regression is one in which the significance of coefficient estimates generated from an ordered logistic regression (the one estimated above) are compared against the distribution of possible coefficient values when the dependent variable vector is randomly permuted (in this case, 1000 times) and new coefficient estimates are generated. The proportion of the extreme value is then calculated, which equals the proportion of randomly generated coefficients that exceed the absolute value of the first stage coefficient estimate (Dekker, Krackhardt and Snijders 2003; Labianca et al. 1998). The proportion of the extreme compares the likelihood that the original coefficient estimate could been randomly generated given the structure of the data. As with traditional 2-tailed significance 
tests, estimates under .1 or .05 are considered 'significant' (Bowler and Brass 2006). The results, presented in Table A2 in the Appendix, confirm all findings presented in Table 1.

\section{[Table A2 about here: Random Permutation Ordered Logit]}

Another issue that may arise is violating the proportional odds assumption of ordered logistic regression. For this analysis, the assumption would only hold if increases in each independent variable equally impact 1 ) the log likelihood of moving from the mutually beneficial payoff category to either the trade-off or zero sum category and 2) the log likelihood of moving from either the mutually beneficial or the trade-off categories to the zero sum category. To test whether this assumption holds, we conduct a Brant test (see Table A3), finding that the assumption fails to hold for both estuary dummy variables, forum size, as well as the IHI variable that captures diversity of forum membership.

\section{[Table A3 about here: Brant Test Results]}

To adjust for this, we estimate a partial proportional odds regression model, where the proportional odds assumption is relaxed only for the forum composition, forum-size, and estuary dummy variables (see Williams 2006, 2014 or 2016 for details). The results, provided in Table A4 in the Appendix, confirm the results regarding the hot-button issues and forum-size. They also show, that increases in forum composition do not increase the log-likelihood of moving 
from the mutually beneficial payoff category to higher levels of conflict, but do increase the log likelihood of moving from either the mutually beneficial or trade-off category to the zero-sum payoff category. Forum-size is positively associated with greater levels of conflict across levels, but is stronger when moving from mutually-beneficial payoffs to higher levels of conflict. Results also confirm that estuary level factors are drivers of conflict, with those in California observing a disproportionate amount of zero-sum games. A Wald Test demonstrates that the updated model does not violate the proportional odds assumption $\left(X^{2}=2.89 ; \mathrm{p}=.823\right)$.

[Table A4 about here: Partial proportional odds Regression Model Results] 
Table A1: Summary Statistics for all Variables Used in Analysis

\begin{tabular}{|c|c|c|c|c|}
\hline & Mean & SD & Min & Max \\
\hline \multicolumn{5}{|l|}{ Individual Level Variables } \\
\hline Neutral Organization & 581 & 493 & 0 & 1 \\
\hline Hot-Button Issues & 1.724 & 897 & 0 & 3 \\
\hline Frequency of Participation & 2.564 & 1.056 & 1 & 5 \\
\hline Breadth of Participation & 3.808 & 1.968 & 1 & 12 \\
\hline \multicolumn{5}{|l|}{ Forum Level Variables } \\
\hline Organizational Diversity & .694 & .1423 & 0 & .838 \\
\hline Forum Size & 24.441 & 29.950 & 0 & 102 \\
\hline Issue Diversity & 2384 & .1078 & 0 & 1 \\
\hline \multicolumn{5}{|l|}{ System Level Variables } \\
\hline Institutional Linkages & 2.441 & .9676 & 0 & 10 \\
\hline Tampa & .357 & 479 & 0 & 1 \\
\hline \multirow[t]{2}{*}{ California } & .483 & 499 & 0 & 1 \\
\hline & \multicolumn{2}{|c|}{ Frequency } & Percer & \\
\hline \multicolumn{5}{|l|}{ Game Payoff } \\
\hline$=$ Mutually Beneficial & \multicolumn{2}{|c|}{587} & \multicolumn{2}{|c|}{50.91} \\
\hline$=$ Trade-Offs & \multicolumn{2}{|c|}{335} & \multicolumn{2}{|c|}{29.05} \\
\hline =Zero-Sum & \multicolumn{2}{|c|}{231} & \multicolumn{2}{|c|}{20.03} \\
\hline
\end{tabular}


Table A2: Ordered Logistic Regression Results with Permutation Test

Individual Level Variables

Neutral Organization

$-0.0233$

0.861

Hot-Button Issues

$0.2301^{* * * *}$

0.002

Frequency of Participation

$-0.1428 * *$

0.024

Breadth of Participation

$-0.0602$

0.101

Forum Level Variables

Organizational Diversity

$1.1267 * *$

0.024

Forum Size

$0.0118^{* * *}$

0.000

Issue Diversity

$-0.3297$

0.597

System Level Variables

Institutional Linkages

.0658

0.368

Tampa

$-.2097$

California

$-0.282$

$.4305 * *$

0.007

Constant

$2.6694 * * *$

0.001

Observations

1380

Proportion of the extreme in parentheses: ${ }^{* * *} \mathrm{p}<0.01,{ }^{* *} \mathrm{p}<0.05,{ }^{*} \mathrm{p}<0.1$ 
Table A3: Brant Test Results

\begin{tabular}{lcc}
\hline & $\chi^{2}$ & p-value \\
\hline Individual Level Variables & .77 & .379 \\
Neutral Organization & .59 & .442 \\
Hot-Button Issues & .05 & .818 \\
Frequency of Participation & .14 & .707 \\
Breadth of Participation & & \\
Forum Level Variables & 4.76 & .029 \\
Organizational Diversity & 10.42 & .001 \\
Forum Size & .00 & .986 \\
Issue Diversity & & \\
System Level Variables & .00 & .957 \\
Institutional Linkages & 8.84 & .003 \\
Tampa & 12.99 & .000 \\
California & 25.14 & .005 \\
All Variables & &
\end{tabular}

A significant test statistic provides evidence that the proportional odds assumption has been violated. 
Table A4: Partial proportional odds Regression Model Results

\begin{tabular}{|c|c|c|}
\hline & $\begin{array}{c}\text { Payoff } \\
1 \text { to } 2 \& 3\end{array}$ & $\begin{array}{c}\text { Payoff } \\
1 \& 2 \text { to } 3\end{array}$ \\
\hline \multicolumn{3}{|l|}{ Individual Level Variables } \\
\hline Neutral Organization & $\begin{array}{c}-0.0269 \\
(0.129)\end{array}$ & $\begin{array}{c}-0.0269 \\
(0.129)\end{array}$ \\
\hline Hot-Button Issues & $\begin{array}{l}0.224 * * * \\
(0.0821)\end{array}$ & $\begin{array}{c}0.224 * * * \\
(0.0821)\end{array}$ \\
\hline Frequency of Participation & $\begin{array}{c}-0.144 * * \\
(0.0646)\end{array}$ & $\begin{array}{l}-0.144 * * \\
(0.0646)\end{array}$ \\
\hline Breadth of Participation & $\begin{array}{l}-0.0613 \\
(0.0383)\end{array}$ & $\begin{array}{l}-0.0613 \\
(0.0383)\end{array}$ \\
\hline \multicolumn{3}{|l|}{ Forum Level Variables } \\
\hline Organizational Diversity & $\begin{array}{c}0.830 \\
(0.536)\end{array}$ & $\begin{array}{c}2.248 * * * \\
(0.800)\end{array}$ \\
\hline Forum Size & $\begin{array}{l}0.0157 * * * \\
(0.00282)\end{array}$ & $\begin{array}{c}0.00613^{* *} \\
(0.00284)\end{array}$ \\
\hline Issue Diversity & $\begin{array}{l}-0.265 \\
(0.639)\end{array}$ & $\begin{array}{l}-0.265 \\
(0.639)\end{array}$ \\
\hline \multicolumn{3}{|l|}{ System Level Variables } \\
\hline Institutional Linkages & $\begin{array}{c}0.0495 \\
(0.0782)\end{array}$ & $\begin{array}{c}0.0495 \\
(0.0782)\end{array}$ \\
\hline Tampa & $\begin{array}{l}-0.389 * \\
(0.211)\end{array}$ & $\begin{array}{c}0.638 * \\
(0.353)\end{array}$ \\
\hline California & $\begin{array}{c}0.188 \\
(0.218)\end{array}$ & $\begin{array}{c}1.418 * * * \\
(0.343)\end{array}$ \\
\hline Constant & $\begin{array}{l}-0.794 * \\
(0.466)\end{array}$ & $\begin{array}{c}-4.097 * * * \\
0.682\end{array}$ \\
\hline Observations & 1059 & 1059 \\
\hline
\end{tabular}


Table 1: Percentage of Respondents Mentioning Different Payoffs

\begin{tabular}{|l|l|l|l|}
\hline & $\begin{array}{l}\text { Mutually } \\
\text { Beneficial }\end{array}$ & $\begin{array}{l}\text { Kaldor-Hicks } \\
\text { Tradeoffs }\end{array}$ & Zero-Sum Game \\
\hline California Delta & 40.37 & 30.28 & 29.36 \\
\hline Tampa Bay & 64.29 & 23.15 & 12.56 \\
\hline Parana & 52.48 & 37.62 & 9.90 \\
\hline
\end{tabular}


Figure 1: Distribution of Payoffs for Individual Organizations and Issues

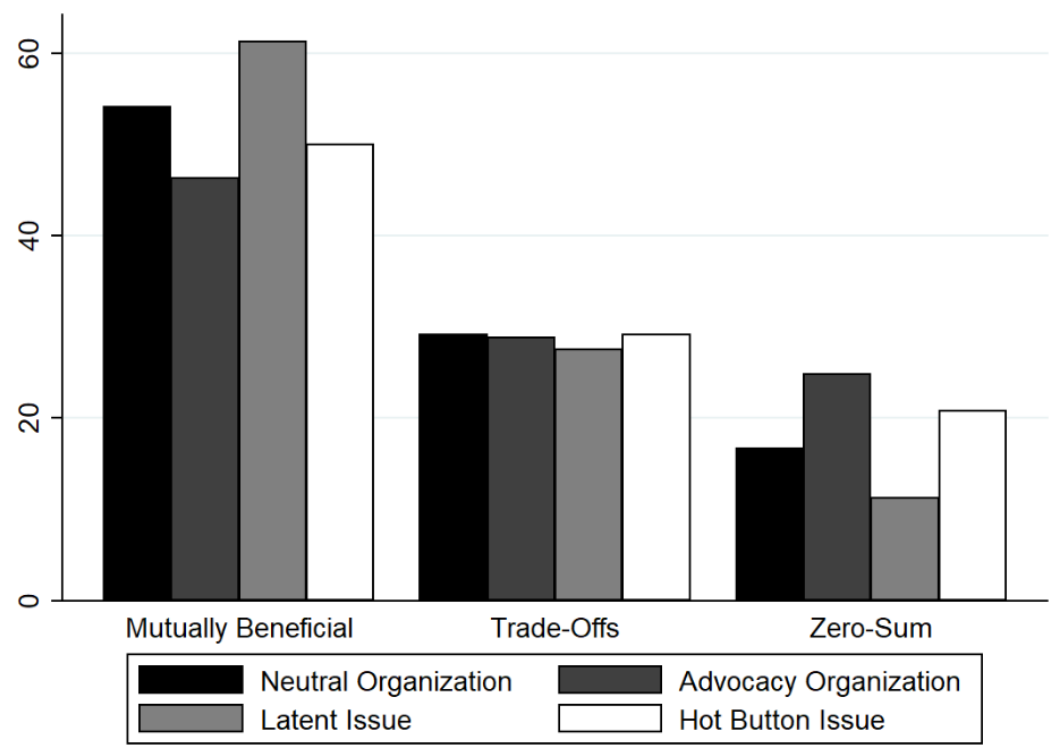


Table 2: Ordered Logistic Regression Results

\begin{tabular}{|c|c|}
\hline \multirow{2}{*}{\multicolumn{2}{|c|}{ Individual Level Variables }} \\
\hline & \\
\hline Neutral Organization & $\begin{array}{c}-0.0234 \\
(0.129)\end{array}$ \\
\hline Hot-Button Issues & $\begin{array}{c}0.230 * * * \\
(0.0821)\end{array}$ \\
\hline Frequency of Participation & $\begin{array}{l}-0.151^{* *} \\
(0.0647)\end{array}$ \\
\hline Breadth of Participation & $\begin{array}{l}-0.0508 \\
(0.0358)\end{array}$ \\
\hline \multicolumn{2}{|l|}{ Forum Level Variables } \\
\hline Organizational Diversity & $\begin{array}{l}1.127 * * \\
(0.522)\end{array}$ \\
\hline Forum Size & $\begin{array}{c}0.0118^{* * *} \\
(0.00239)\end{array}$ \\
\hline Issue Diversity & $\begin{array}{l}-0.330 \\
(0.640)\end{array}$ \\
\hline \multicolumn{2}{|l|}{ System Level Variables } \\
\hline Institutional Linkages & $\begin{array}{c}0.0658 \\
(0.0784)\end{array}$ \\
\hline Tampa & $\begin{array}{l}-0.210 \\
(0.203)\end{array}$ \\
\hline California & $\begin{array}{c}0.431^{* *} \\
(0.208)\end{array}$ \\
\hline Constant Cut \#1 & $\begin{array}{l}1.135^{* *} \\
(0.456)\end{array}$ \\
\hline Constant Cut \#2 & $\begin{array}{c}2.669 * * * \\
(0.463)\end{array}$ \\
\hline Observations & 1059 \\
\hline
\end{tabular}

Standard errors in parentheses: ${ }^{* * *} \mathrm{p}<0.01,{ }^{* *} \mathrm{p}<0.05,{ }^{*} \mathrm{p}<0.1$ 